\section{Os equívocos de Peirce}

\section{RESUMO}

Este texto pretende mostrar os equívocos, deficiências e inexatidões da teoria semiótica de C. S. Peirce tão utilizada em pesquisas sobre imagens, textos e expressões em geral no Brasil. 0 autor problematiza certos conceitos-chave dessa teoria e prega a necessidade de se realizar uma investigação rigorosa de seus escritos. Para isso, ele se propõe a dar início a essa tarefa discutindo o conceito de "interpretante".

\section{ABSTRACT}

Charles Sanders Peirce is a prestigious and important point of reference within semiotic circles and in investigations on communication in Brazil. Whole research institutions take his writings as basic text, sometimes as the exclusive text to build up the research and methodology instruments for investigations on image, text and expression in general. But nobody cares about his deficiencies, his inexactness, his equivocalness. As, for example, the consequences of the reduction of the logic to the semiology; the statement that the man is thought and the dream is "irresponsible"; the paradox between sign as "living thing" and its substantial depth; the ceasing of the semiosis; the tendency of the pragmatism to converge to the positivism; the Hegel's character of his "absolute object" and the submission of his purpose under an Idealism in metaphysical basis; finally the boundaries of his reasoning and of his concept of truth. In fact, it is difficult to work with an author who at the same time in which he operates with an nominalist-scholastic model, he tries to absorb the change and the transformation dimension of reality; an author who speaks about the rooting of the sign within the no-symbolic sphere at the same time as he uses an structural order fixed only in symbols. That is the reason why it is necessary to investigate accurately his writings and that is what we shall do here starting from his concept of interpretant.

\section{PALAVRAS-ChaVe (KEY WORDS)}

- Semiótica de Peirce (Peirce Semiotics)

- Interpretante (Interpretant)

- Pesquisa em Comunicação (Communication Research)

\section{Ciro Marcondes Filho} USP
O FILÓSOFO NORTE-AMERICANO Charles Sanders Peirce desfruta nos estudos lingüísticos e de comunicação uma posição de prestígio quase inabalável em vista de sua proposta semiótica, de seu modelo teórico de interpretação de imagens e mensagens, de seu processo cognitivo como um todo. Poucos se preocuparam em fazer uma leitura de seu modelo buscando insuficiências, equívocos ou aporias. Derrida, como veremos abaixo, exclui sua concepção de linguagem como jogo no mundo, advertindo que é preciso ir mais a fundo na questão do sentido do ser, e buscar, isso sim, o jogo do mundo.

De fato, é complexo trabalhar com um autor que ao mesmo tempo em que se usa de um modelo nominalista escolástico absorve a dimensão da mudança e da transformação, que fala em enraizamento do signo no não-simbólico associado a uma ordem estrutural firmada apenas nos símbolos. Por isso, é preciso trabalhá-lo detalhadamente e esta leitura terá como nuclearização a noção de interpretante em Peirce.

De fato, é complexo trabalhar com um autor que ao mesmo tempo em que se usa de um modelo nominalista escolástico absorve a dimensão da mudança e da transformação, que fala em enraizamento do signo no não-simbólico associado a uma ordem estrutural firmada apenas nos símbolos. Por isso, é preciso trabalhá-lo detalhadamente e esta leitura terá como nuclearização a noção de interpretante em Peirce.

Peirce constituiu sua base intelectual a partir de Aristóteles, se bem que no decorrer de sua produção intelectual o tenha submetido a "muitas reformas". No núcleo de seu conceito fenomenológico de faneron, que estrutura sua proposta semiológica, encontramos um nominalismo medievalista de Duns Scot recuperado por este "realista escolástico", como ele mesmo diz, que não crê no evolucionismo spenceriano mas apoia-se nos sistemas de Hegel e Schelling, se bem que seus alicerces lhe pareçam pou- 
co confiáveis. Por isso, Peirce evoca um idealismo objetivo em seu trabalho, ao mesmo tempo em que a recusa da coisa em si kantiana [cf.5.525].

O nominalismo de Duns Scot é uma reação contra o primado do intelecto associado a uma certa leitura de Aristóteles. Trata-se de uma escolástica mais tradicional que a de São Tomás, que atribui a fé na razão e que se apóia numa teoria de indução, onde o que importa é a experiência. Há uma precedência da vontade como causa total dos atos e dos fatos.

A fenomenologia de Peirce não contempla a intencionalidade como a de Husserl; ao contrário, para ele, o faneron simplesmente é, mais nada. Pura afecção, apenas algo um nível acima da impressão orgânica e um nível abaixo da sensação e da idéia. Nesse momento, o da pura afecção, ainda não há nada investido. No momento seguinte já há um sujeito que responde a essa afecção, mas ainda sem intencionalidade, reagindo a ela apenas com um "esforço de resistência". É somente numa terceira fase que essa afecção se impregna de significação e se torna um hábito, ou uma lei se se referir a um objeto. Esses três momentos, que alguns chamam de primeiridade, secundidade e terceiridade, serão tratados aqui como primeirismo, secundismo e terceirismo para melhor individualizar cada conceito, para valorizar sua originalidade peirceana e para evitar desvios lingüísticos causados pelo desgaste daqueles termos, na forma como hoje são usados.

Do ponto de vista da ciência, Peirce foi, enquanto matemático, precursor de Russell e Whitehead. Sua fenomenologia ou faneroscopia impregnaram a ciência americana do "espírito de laboratório", como prega sua versão de pragmatismo. Próximo ao positivismo lógico do Círculo de Viena, Peirce batalha igualmente pelo abandono do misticismo e pela união com a ciência. Seu projeto pragmático procurava demonstrar a falta de sentido, mesmo o absurdo das afirmações metafísicas. Há que se considerar, conforme mencionamos no volume um desta Trilogia, que a campanha contra a metafísica dos positivistas lógicos ultrapassava em muito a simples recusa da metafísica propriamente dita, incluindo sob esse rótulo áreas do conhecimento absolutamente sérias e respeitáveis como a história, a psicanálise, a filosofia especulativa, a economia política, etc.

No campo especificamente teórico dos signos, Peirce e Saussure falam ambos de um signo incorpóreo, mas, enquanto este último o vê de um ponto de vista lingüístico e espírito, Peirce opera num plano lógico e categorial. Melhor do que Saussure, o filósofo americano era mais atendo àquilo que Derrida chama de "irredutibilidade do devir imotivado". Ou seja, ao fato de o signo não ter ligação natural com um determinado significado, com um "motivo", de nem ele, nem o símbolo de fato existirem, mas de haver apenas um devir signo do símbolo. O devir está associado à idéia peirceana de o símbolo crescer, como veremos mais à frente.

Passemos, então, àquilo que consideramos as incongruências ou os equívocos de Peirce. Separamos sete pontos, no mínimo polêmicos, do pensador norte-americano relacionados ao campo inovador em sua obra, a semiótica e a noção de interpretante: a redução da lógica à semiologia e suas conseqüências; a afirmação de que o homem é pensamento e o sonho é irresponsável; o paradoxo entre o signo como coisa viva e a "profundidade substancial"; a parada da semiose; a tendência do pragmatismo convergir para o positivismo; a marca hegeliana de seu "objeto absoluto" e a submissão de seu modelo a um idealismo de fundo metafísico e, por fim, os limites de sua razão e de sua verdade.

A semiótica peirceana é composta de três partes: gramática pura, lógica crítica, retórica pura. A primeira fala da verdade do signo, do que é nele verdadeiro para expressar um sentido; a segunda, de como essa verdade se aplica a um objeto, ou das "condições de verdade" da representação para que essa ciência possa ser verdadeira; a terceira, trata das leis pelas quais um sig- 
no nasce de outro, um pensamento engendra outro.

Detenhamo-nos um pouco no plano da gramática, ou seja, o do signo ou representamen. Signo, para Peirce, "representa" algo para a idéia que provoca ou modifica (o termo usado para representar aqui é stands for, no sentido da materialidade, de algo que vale como). Ele é um veículo que comunica à mente algo do exterior (339). $\mathrm{O}$ representado é seu objeto, o comunicado é a significação e a idéia que provoca é seu interpretante. Em outro lugar (177), ele diz que signo é um cognoscível, que, por um lado, é determinado por algo diferente dele (seu objeto); por outro, determinando, ele mesmo, uma mente existencial ou potencial. Essa mente interpretante é determinada pelo objeto.

Vamos trabalhar essas categorias mais detidamente. Retornemos à indicação feita acima de faneron: há uma afecção, há um sujeito que responde à afecção, mas ainda com um "esforço de resistência" e há, por fim, uma significação que impregna a afecção. Muito bem, isso quer dizer que o signo em Peirce é existência, sentimento e mediação. Quando alguma coisa me afeta, ocorre essa tríplice elaboração.

Uma coisa pode me afetar de três maneiras, conforme o grau de semelhança que ela possui com o fato natural. Eu posso ver um desenho, uma fotografia, uma estátua de algum animal e isso me remeter diretamente a ele; há alto grau de similaridade. Essa primeira forma sígnica é um ícone da coisa, espécie de cópia mais ou menos fiel do dado natural e em alguns casos não há mesmo diferença entre ele e o objeto que o representa. Uma segunda forma sígnica é aquela que não se assemelha ao objeto mas indica-o, remete a um ausente, o denuncia: um furo indica um tiro, uma fumaça indica um fogo, etc. Trata-se do índice. Por fim, os símbolos que já não tem nenhuma relação de similaridade com a coisa que representam: a bandeira, a palavra, etc.

Uma primeira dificuldade se coloca aqui. Peirce diz que o símbolo está enrai- zado no não-simbólico. Derrida chama a atenção para esse fato na pág. 70 de sua Grammatologie, onde ele diz: Peirce faz justiça a duas exigências aparentemente incompatíveis. O erro seria aqui sacrificar uma pela outra. É preciso reconhecer o enraizamento do simbólico (no sentido de Peirce: do "arbitrário do signo") no não-simbólico, numa ordem de significação anterior e ligada: "Symbol grow. They come into being by development out of other signs, particularly from icons, or from mixed signs...". Mas este enraizamento, prossegue ele, não deve comprometer a originalidade estrutural do campo simbólico, a autonomia de um domínio, de uma produção, de um jogo: "So it is only out of symbols that a new symbol can grow. Omne symbolum de symbolo".

Derrida reclama que nos dois casos o enraizamento genético remete de signo a signo, não deixando nenhum chão à nãosignificação que pudesse se estender para fundá-lo sob o jogo e o devir dos signos. Diz também que a própria lógica, a lógica não-formal baseada num valor de verdade, se subsume ao modelo semiológico do filósofo americano, reduzindo-se a uma posição secundária. E é aqui que o modelo de Peirce é mais frágil, pois sua desconstrução do significado transcendental não deixa vínculos. Trata-se apenas de uma doutrina formal de condições às quais o discurso deve satisfazer para ter um sentido, para "querer dizer", não importando se ela é falsa ou contraditória.

A desconstrução do significado transcendental, continua Derrida, vai muito longe em Peirce, instalando um termo tranqüilizador do reenvio de signo a signo. Nisso o filósofo francês localiza logocentrismo e metafísica da presença em Peirce. O reenvio permanente dos signos entre si é inaceitável, por exemplo, a Husserl, pois, enquanto este fala do conceito de signo e da manifestação da presença, Peirce fala de re-presentação e apresentação originária da mesma coisa. Peirce diz, por exemplo, que a manifestação, ela mesma, não revela uma presença, "ela engendra signo" (elle fait sig- 
ne), não havendo aí uma fenomenalidade reduzindo o signo ou o representante para deixar enfim a coisa significada aparecer sob o brilho de sua presença. A própria coisa é já um signo (representamen) subtraído à simplicidade da evidência intuitiva, diz Derrida. O signo (representamen) só funciona suscitando um interpretante que torna-se, ele mesmo, signo e assim continuamente.

Peirce arruína a noção de signo no momento em que ele é mais necessário, continua o filósofo, só havendo portanto signos pelo fato de existir sentido (neles); afinal, diz Peirce, nós só pensamos em signos. Mas isso é inaceitável. Derrida diz que o jogo não é o jogo no mundo, como o querem alguns lingüistas americanos (pensemos, por exemplo, em Rorty), que usando-se da lógica do jogo expulsam o problema do sentido de suas pesquisas. Para ele, ao contrário, trata-se de pensar o jogo na linguagem. Para pensar o significado do jogo, conclui o pensador francês, é preciso inicialmente esgotar com seriedade a problemática ontológica e transcendental, transcender paciente e rigorosamente a questão do sentido do ente, do ser do ente e da origem transcendental do mundo - a mundaneidade do mundo - seguir efetivamente e até o final o movimento crítico das questões husserlianas e heideggerianas, conservar sua eficácia e sua visibilidade.

Mais ainda: Peirce diz com todas as letras, que o pensamento só é possível dentro dos signos. Que o pensamento que não possa conhecer-se não existe, que todo pensamento deve necessariamente existir em signos (251). Isso porque, não há elemento da consciência que não possua algo correspondente na palavra (314). A razão é óbvia, diz ele: é que a palavra ou o signo usado pelo homem são o próprio homem. Se cada pensamento é um signo e a vida é uma corrente de pensamento, o homem é um signo; o fato de cada pensamento ser um signo exterior prova que o homem é um signo exterior.

Este reducionismo ("o homem é o pensamento") pode-se dever tanto ao desconhecimento de Peirce da psicanálise quando à sua virtual desqualificação. Peirce dizia que o sonho não pertence ao terceirismo; pelo contrário, ele é completamente irresponsável; o objeto da experiência como realidade é segundo. Mas o desejo que busca ligar um ao outro é terceiro, é medium (342). Recordando que o terceirismo é a conexão entre fenômenos de primeiro tipo (sensações puras: cores, sons, odores) e de segundo tipo (uma coisa acontece a outra: um choque, por exemplo), Peirce, dizendo que ele é "totalmente irresponsável" leva a supor que algo não se encaixa nesse jogo e que portanto deve ser desconsiderado.

Aqui a relação de Peirce com o inconsciente difere não somente da de Freud como da de Nietzsche. Para este último, ele está no mesmo campo das formas mencionadas ao tratarmos do inexprimível (escritura não-linear, a musicalidade, os afetos): não há representação, é apenas projeção da coisa, do instinto. Ele é determinante e, ainda segundo Nietzsche, dar primazia à consciência significaria o privilégio do desconhecimento, da não-maturação, do inacabamento, pois a consciência aflora e se expõe socialmente nas situações em que os homens se comunicam, se usam da linguagem. Peirce, diferentemente, refuta o que não pode ser apreendido empiricamente pela sua fenomenologia: o que conta é só o plano dos signos que comunicam algo, o que para o filósofo alemão é uma dimensão menor da vida. A consciência para Nietzsche é supérflua em coisas essenciais, é a parte mais ínfima, mais epidérmica e pior de todo o pensamento. A opção de um estudioso da linguagem acaba tendo que ser ou ficar no campo das evidências e das relações fenomenológicas diretas ou então ousar entrar em comunicação com campos menos transparentes.

Esse fato não tem nada a ver com a metafísica, visto ser Nietzsche o primeiro grande pensador a orientar toda sua expressão filosófica para combater o logocentrismo e a ontoteologia, exatamente por 
estas tentarem ir buscar uma centralidade, um sistema de valor e de verdade fora da própria estrutura, como vimos na crítica de Derrida ao estruturalismo.

Se para Nietzsche o sonho é soberano e nada podemos em relação ao que sonhamos, Freud o vê como algo individual e uma forma de realização de desejos. Já não é o "inconsciente puro", de que falava Nietzsche, mas uma elaboração mental, o trabalho do sonho, que, para Freud torna-o interpretável. Há uma linguagem, marcada por mecanismos de condensação, deslocamento e sobredeterminação para dizer, de forma indireta, aquilo que não pode ser dito ou mesmo pensado claramente.

Este plano, que é onde Derrida localiza o desbravar (as primeiras experiências da infância como marcas numa folha, desaparecendo da mente consciente quando a criança cresce e que deixam traços nos estratos mais profundos da psique, como as marcas deixam traços na cera), a pista (Spur), que por sua vez remete à diferança. O conteúdo inconsciente é o dos representantes das pulsões, dos recalques; são o processo primário (algo tão original com os fatos do primeirismo peirceano), que serão depois (negativamente, segundo Nietzsche) trabalhados na linguagem.

Há em Freud uma esperança de que os conteúdos inconscientes tornem-se conscientes (Wo Ich war soll Es werden), e nessa direção segue sua Interpretação de sonhos. Ou seja, Freud acredita num deciframento, numa tradutibilidade, no encontro das chaves para dissolver o enigma da "língua" do inconsciente, mas não se pode dizer que tenha tido pleno sucesso em sua empreitada.

O que, por outro lado, não justifica a afirmação de Peirce de que o pensamento só é possível dentro dos signos, fazendonos retornar à mesma crítica feita a Rorty, no capítulo respectivo, no qual o filósofo americano pretendia excluir do campo do real tudo aquilo que não era lingüisticamente exprimível. Mas viu-se que isso não é possível, pois, sem querer fazer qualquer alusão à linguagem interior de Husserl, co- municam-se outras formas, outros processos e mesmo o silêncio, de forma fortemente expressiva.

A terceira objeção a Peirce, assim como as demais, serão desenvolvidas a partir do estudo de Pierre Thibaud (notação: Th, xx), que se ocupou exclusivamente com o interpretante de Peirce.

A noção de interpretante evoluiu em Peirce entre 1895 e 1897. No primeiro caso, tínhamos uma definição intelectualista, diz Thibaud: um signo representa qualquer coisa em relação à idéia que ele produz ou modifica. O que ele representa são o objeto e a idéia que faz nascer, seu representante. Dois anos depois, Peirce já não diz que interpretante é idéia mas signo: “Um signo ou representamen é alguma coisa que representa alguma coisa para alguma pessoa sob alguma relação ou a algum título. Ele se dirige a alguém, isto é, cria no espírito desta pessoa um signo equivalente, dir-se-ia, mais desenvolvido. Este signo criado, eu chamo de interpretante do primeiro. $\mathrm{O}$ signo representa alguma coisa, seu objeto. Ele representa este objeto não em relação a tudo mas por referência a um tipo de idéia que eu chamei algumas vezes de fundamento (ground) do representamen" [2.228].

Aqui está, assim, também introduzido o conceito de ground: a idéia diz respeito ao ground, é a forma como o objeto é visto, o perfil, de acordo com o qual ele é tratado na representação. O ground dilacera o objeto, é o ângulo pelo qual se apreende o mesmo. Daí, também, a própria noção de objeto: $\mathrm{O}$ objeto do signo não é, assim, uma coisa concreta dada. Ele só existe na medida em que é pensado, captado através de uma multiplicidade de quadros de referência. Por exemplo, quando eu falo "este cachorro", refiro-me a algo presente aqui e agora mas vinculado a uma noção primitiva. (Thibaud fala que o ground explode o objeto em uma multiplicidade de aspectos que são as tantas reduções de sua hecceitas primitiva; Th, 7). Ground é a forma como eu apreendo hoje, aqui, a coisa, por meio de seu representamen. O objeto imediato é o resultado dessa 
apreensão.

Mas objeto imediato não é o mesmo que objeto dinâmico. Este último é o objeto tal qual ele é, real, imaginável ou não, que, por um meio ou outro, vem determinar o signo à sua representação [4.536]. Objeto imediato é o objeto tal qual o signo o representa e do qual o ser é dependente de sua representação no signo. Não obstante, o objeto dinâmico também é signo, emana dele, difere dele apenas por transcendê-lo.

Pelo fato de o signo só poder representar o objeto de uma certa maneira, decorre que a representação é muito limitada: o signo só pode representar o objeto e dizer alguma coisa dele. Ele não pode nem dar a conhecer nem a reconhecer esse objeto [2.231]. O signo, assim, indica o objeto dinâmico, orientando o sujeito a uma experiência deste último: o intérprete vai descobrir por uma experiência colateral. O objeto dinâmico é apenas uma possibilidade concreta, que só admite realidade pelo processo de interpretação, por meio de interpretantes que vão explicar com novos signos aquilo que o representamen escolhe do objeto dinâmico em função do ground (Th., 10).

Peirce ilustra seu quadro conceitual com a frase "O sol é azul". Neste caso, o objeto dinâmico, a variedade de acepções do sol, é representado por uma descrição exaustiva da estrela. Essa descrição torna possível o aparecimento do objeto imediato através do ground instituinte do signo.

O objeto dinâmico se desdobra nos três planos de simulitude apontados acima (ícone, índice e símbolo), sendo que o fenômeno representacional, como modificação efetiva, surge no índice e, como associação regulada, que necessita de aprendizagem, no símbolo.

Mas o que vem a ser o interpretante? Ele é o conjunto de todos os fatos conhecidos em relação a um objeto. Diz Thibaud, que a experiência induzida pelo signo é dupla: é tanto centrada no ground como no objeto dinâmico. Contudo, é pelo ground que se fixa o quadro de referência e a interpretabilidade. Mas para conhecer o signo deve- se juntar também as convenções do sistema de símbolos e a experiência colateral. Short dá um interessante exemplo: Consideremos vários médicos à cabeceira de um paciente, em concordância sobre o fato de que a leitura do termômetro indica a existência de uma febre no doente, mas em desacordo sobre a interpretação do fenômeno. $\mathrm{O}$ objeto dinâmico é a condição física atual do doente, na forma em que ela coloca um problema à medicina, o objeto imediato do signo é a febre e os interpretantes dependerão das observações colaterais, às vezes do doente em questão e dos casos similares, feitos por diversos médicos.

\section{Detalhamentos}

A formação intelectual de Peirce: Peirce, C. S. "Escritos coligidos". In: Peirce e Frege, Os Pensadores, op. cit. Schelling-Hegel, está na pág. 113; a forte influência de Duns Scot, na pág. 114; "Eu próprio sou um realista escolástico de uma facção algo extrema", p. 129. Sobre o evolucionismo: "Aprendi pouco com os evolucionistas; as teorias deles são apressadas" (p. 114).

Sobre Duns Scot, consultar Gandillac, v. Bibliografia.

O idealismo objetivo de Peirce: as leis e as diversas regularidades, Peirce toma de um quadro que ele clama de "idealismo objetivo": "A única teoria inteligível do universo é a do idealismo objetivo, segundo a qual a matéria é o espírito enfraquecido ('effete mind'), os hábitos inveterados tornando-se leis físicas" [6.25, cf. 6.277].

Duns Scot, o nominalismo e o modelo de Peirce: "Peirce toma emprestado de Duns Scot a idéia de que os 'universais' - ele fala 'gerais' - são reais; mas estes se descobrem, por inspeção indutiva experimental (não intuitiva), sendo fanerons. E parece que Peirce teria achado pouco fenomenológica (e pode-se interpretar neste sentido o único texto de Peirce sobre Husserl que se conhece) esta atribuição a priori da intencionalidade ao faneron, pois, antes de ser 
intencional, o faneron é, não há nada mais a dizer disso: ele é, como a 'afecção simples' de Maine de Biran, 'de um grau acima da impressão orgânica', mas 'ainda abaixo da sensação e da idéia'. É o estado primeiro do faneron, categoria primeira da faneroscopia. Não pode haver aí, nesta etapa, nenhuma intencionalidade fenomenológica, pois esta 'quantidade de sentimento' ou 'quantidade sentida', à qual Peirce designa a 'afeição simples' não é nem subjetiva, nem objetiva, nem ativa, nem passiva, menos ainda intencional: ela é tida. Num segundo tempo, ele vai reencontrar, por assim dizer, o sujeito da sensação: ela existirá para ele para que ele responda à sua presença 'pura' (o hic et nunc de Duns Scot). É a segunda categoria da fenomenologia peirceana. Não há lugar aqui tampouco para a intencionalidade: o sentido está lá enquanto sentido, isso é tudo; não há ainda essência por si mesma: ela existe para o cogniscente, sem mais, na 'dupla consciência do esforço e da resistência'. É o que permite aproximar mais uma vez Peirce a Maine de Biran. A terceira categoria da fenomenologia de Peirce é a única em que a intencionalidade - mas num sentido que não pode ser totalmente sobreposto àquele de Husserl - pode se dar. Por ela, o primeirismo da 'afecção simples' está ligado ao secundismo do 'esforço de resistência'; e o terceirismo é geral: do lado do sujeito ela é hábito, do lado do objeto é a lei. Ela tem, portanto, como a intenção husserliana, unidade e bipolaridade: unidade da 'essência', da 'generalidade', portanto, com Duns Scot - e Husserl -, ele afirma a realidade independentemente do primeirismo e do secundismo (o faneron é geral em si); polaridade humana pelo hábito, polaridade física pela lei. Mas, assim procedendo, o terceirismo peirceano redireciona as barreiras da époché e diz algo de verdadeiro sobre o homem e o mundo". Cf. Deledalle, v. Bibbliogr.

Peirce vai mais longe que Husserl, cf. Derrida: "Peirce considera a indefinição do reenvio como o critério que permite reconhecer que se trata de um sistema de signos. O que desencadeia o movimento de significação é o que torna a interrupção impossível. Proposição inaceitável para Husserl, para quem a fenomenologia permanece por isso - isto é, no seu 'princípio dos princípios'- a restauração mais radical e mais crítica da metafísica da presença". Derrida, p. 72. Em Peirce, faneron é tudo que é presente no espírito, com ou sem correspondência com o real (284).

Sobre o devir imotivado do símbolo, ver Derrida, 69-70.

Gramática pura, lógica crítica, retórica pura: as três partes da semiologia de Peirce: "A ciência da semiótica tem três áreas. A primeira é chamada por Duns Scot grammatica speculativa. Poderíamos chamá-la gramática pura. Ela tem por tarefa determinar aquilo que deve ser verdadeiro do representamen, utilizado por qualquer espírito científico para que possa exprimir um sentido qualquer. A segunda é a lógica propriamente dita. É a ciência daquilo que é quase necessariamente verdadeiro dos representamina de qualquer inteligência científica para que ela possa ter um objeto qualquer, isto é, ser verdadeira. Em outros termos, a lógica propriamente dita é a ciência formal das condições de verdade das representações. A terceira área, eu chamaria, imitando a forma de Kant, quando ele restaura as velhas associações de nomes instituindo uma nomenclatura para as novas concepções, retórica pura. Ela tem por tarefa determinar as leis segundo as quais, em qualquer inteligência científica, um signo dá nascimento a outro, e, mais especialmente, segundo as quais um pensamento engendra um outro". Peirce, Philosophical writings, cap. 7, p. 99. Ver também a esse respeito Daledalle: "Lógica crítica é a teoria quase necessária ou formal dos signos. Ela se ocupa daquilo que é exigido para que o representamen se relacione com um objeto de uma maneira verdadeira. A retórica especulativa trata das 'condições gerais da referência dos símbolos e outros signos aos interpretantes que eles determinam'. É um outro nome do pragmatismo, que é a teoria da significação 
dos signos ou, mais exatamente, o método de determinação da significação dos signos. 'Considerem, escreve Peirce num artigo de 1905, quais são os efeitos práticos que vocês pensam que podem ser produzidos pelo objeto da concepção de vocês: a concepção de todos esses efeitos é o todo de sua concepção'. Quando se lê, num operacionalismo como o de P. W. Bridgam, que a significação de um conceito `não é outra coisa senão um conjunto de operações'; quando se lê num positivismo lógico, como o de Carnap, que 'a significação de uma frase é, num certo sentido, idêntico à forma pela qual determinamos sua verdade e sua falsidade'; e, como em Wittgenstein, que `a significação é o uso que fazemos de uma palavra', percebe-se que é a um apelo que Peirce que os filósofos americanos respondem quando se colocam sob a bandeira do operacionalismo, do positivismo lógico e da análise lingüística. A gramática pura ou especulativa, enfim, é a ciência dos signos enquanto tais". Deledalle, op. cit., p. 1181.

As menções de Nietzsche em relação ao inconsciente encontram-se mais desenvolvidas em Marcondes Filho, Da arte..., 2003, “Os filósofos e a comunicação", assim como no extrato do mesmo, intitulado "Introdução a Friedrich Nietzsche".

Freud acreditava numa possível tradução dos conteúdos inconscientes: uma discussão sobre os diferentes usos da expressão freudiana Wo Es war soll Ich werden (Onde havia id deve ego estar) pode ser encontrada em Marcondes Filho, C., A sociedade.... Sobre Freud e os equívocos de sua interpretação de sonhos, ver: Marcondes Filho, C., A produção...

Pierre Thibaud trabalhou intensivamente com o intepretante de Peirce (V. Bibliogr). Convém chamar a atenção aqui ao fato de Thibaud separar o conceito de signo do de representamen, conforme a citação de Peirce: “Todos os signos comunicam noções [de um objeto] aos espíritos humanos, mas não vejo nenhuma razão para que todos os representamen devam fazâ-lo" [1540]. Neste caso, Umberto Eco propõe o critério de considerar que o signo se apresenta como elemento concreto ("token"), utilizado no processo de comunicação e referência, enquanto que o representamen aparece como o elemento abstrato ("type"), ligado a um certo conteúdo; no primeiro caso, ter-se-ia uma semântica extensional e, no segundo, uma semântica da pura intenção, sem ligação com o referente e com noção autosuficiente de conteúdo (cf. Thibaud, 5). No caso de nosso ensaio, manteremos os dois termos tratados como sinônimos, já que o objetivo não é o de aprofundar essa distinção.

Assim define Peirce o termo "ground"...: Ground de um signo são as "características comuns" de seu objeto. O ground é, de fato, um atributo do objeto, na medida em que este objeto foi escolhido de uma certa forma e que alguns de seus atributos foram considerados pertinentes (na expressão "esta mesa é encerada", deve-se bem ver que a mesa poderia ser também percebida e descrita como sólida, bela, etc.). O ground não é portanto o signo-veículo, porque este último possui múltiplas características que não são pertinentes naquilo que concerne à sua função de signo. O ground é o ponto de vista segundo o qual o signo-veículo é interpretado como signo de seu objeto (numa amostra de cores funcionando como signo da cor da pintura que eu quero comprar, somente a cor da amostra constituirá o ground e não o fato de que ela possa ter tal forma ou ser feita de tal material). [2.418]

...e o objeto dinâmico. Um objeto dinâmico também está no universo do signo: ele emana do signo. Se ele pode determinar um signo à sua representação [4.536] é porque ele mesmo é um signo: “Todo signo representa um objeto independente dele mesmo, mas ele só pode ser signo deste objeto na medida em que este objeto tem, ele mesmo, a natureza de um signo, de um pensamento. Pois o signo não afeta o objeto mas é afetado por ele, de sorte que o objeto deve ser capaz de comunicar um pensamento, isto é, deve ter a natureza de um pensamento ou de um signo" [1.538].

O exemplo dos médicos e do paciente, está 
em Short, T.L., (v. Bibliogr)..

\section{Os interpretantes}

A partir dessa definição de conceitos podemos proceder à construção de interpretantes. A significação em Peirce não é uma relação do signo com um objeto mas do signo com o interpretante e o sentido se constrói pela seqüência de interpretantes: Por sentido de um termo entendemos o interpretante geral inteiro [5.179]. A regra desta seqüência é a simples regra de tradução de um signo em outro. Isso pode ser visto com o exemplo que Peirce dá das possíveis definições do lítio: ou simplesmente como elemento de peso atômico 7 ou por uma longa descrição que faz surgir o mineral a partir de processos químicos de evaporação, refinamento, conversão, fusão, etc.

Assim, o sentido (os interpretantes) de um termo - o profundo (depth) em oposição ao leve (breath) - aparece ligado à informação, que representa uma medida de predicação e que se pode analisar como a soma das proposições sintéticas nas quais o símbolo é sujeito ou predicado [2.418]. E aqui Peirce irá procurar se separar do positivismo estreito, buscando incluir na interpretação as formas de vida, através do conjunto de interpretantes de um termo, ou seja, de sua "profundidade substancial". Formas de vida remetem a um tipo de pulsação, à coisa viva: “Todo símbolo é uma coisa viva, num sentido muito restrito que não é uma figura de retórica. O corpo do símbolo muda lentamente, mas sua significação cresce inevitavelmente, incorporando novos elementos e rejeitando os antigos" [5.594].

Nesta bela construção de Peirce, vêse, contudo, os sinais de sua ambigüidade. Tivesse ele se mantido na primeira parte da frase teria ainda se resguardado das possíveis críticas. Ao dizer que o símbolo é coisa viva e que isso não é apenas uma figura de retórica, Peirce rompe com o aristotelismo estreito que marca sua metafísica da essência, herança da escolástica de Duns Scot, ao mesmo tempo em que incorpora o mo- vimento de Heráclito. Mas isso não dura: a continuação da frase freia nossas expectativas: a profundidade substancial trai uma filiação à metafísica da presença e à ontoteologia. Por mais que haja mudanças, a coisa permanece. Não existe, assim, a contingência, a provisoriedade, o puro jogo, mas a fixação em categorias que vão se constituindo sucessivamente. Veremos isso melhor mais adiante.

A evolução do interpretante tende ao infinito: um signo faz com que seu interpretante seja novamente visto como signo de um novo interpretante e assim sucessivamente [cf. 2.303]. Assim, diz Thibaud, toda representação abre-se necessariamente sobre um processo de regressão ao infinito, sendo o objeto da representação nada mais que "uma representação em que a primeira representação é o interpretante". E daí vem o objeto absoluto de Peirce: "Uma seqüência sem fim de representações, cada uma representando aquela que a precede, pode ser concebida como tendo um objeto absoluto como limite. O sentido de uma interpretação não pode ser outra coisa que uma representação... De sorte que existe aí uma regressão infinita. Definitivamente, o interpretante nada mais é do que uma representação que recebe, abrindo caminho, a chama da verdade; e, enquanto representação, há novamente seu interpretante. Vê-se bem que é uma outra série infinita" [1.339].

Neste ponto colocam-se mais duas objeções à teoria semiótica de Peirce, a que se refere ao "objeto absoluto" e aquela relativa à "chama da verdade". Mas não nos ocuparemos com essas questões no momento; elas reaparecerão mais adiante e lá serão comentadas. Continuemos a acompanhar a descrição de Peirce.

Peirce diz que não há signo sem interpretante, que é o "pivô de todo o processo semiótico" (Thibaud). Meu interpretante é qualquer coisa que se vincula essencialmente a tudo que opera como signo. Um signo é somente um signo em ato por receber uma interpretação, isto é, pelo fato que ele determina um outro signo do mesmo objeto. Daí 
se constatar que Peirce vincula-o ao terceirismo. Podemos mesmo associar par a par os termos da seguinte forma: signo, objeto e interpretante equivalem a primeirismo, secundismo e terceirismo.

$\mathrm{Na}$ discussão entre o interpretante e a realidade pode-se imaginar como encontrar objetos reais e dar nascimento à experiência concreta. Para isso, Peirce constrói a categoria do interpretante final. Este é a associação entre o mundo dos sentidos e o objeto dinâmico. Pode-se dizer que há, em Peirce, três interpretantes: imediato, dinâmico e final. Na carta a Lady Welby, Peirce diz: "Meu interpretante imediato está implicado no fato que todo signo deve ter sua própria interpretabilidade antes de ter um intérprete. Meu interpretante dinâmico é aquele no qual eu realizo a experiência em cada ato de interpretação e é diferente de um interpretante para outro. $\mathrm{O}$ interpretante final é o resultado interpretativo ao qual todo intérprete é levado a chegar se o signo for suficientemente considerado. $\mathrm{O}$ interpretante imediato é uma abstração, consistindo numa possibilidade. $\mathrm{O}$ interpretante dinâmico é um acontecimento real único. $\mathrm{O}$ final é aquilo para onde tende o interpretante real".

Thibaud vê neste processo o caráter teleológico de todo processo semiótico: cada signo adquire seu sentido não somente em relação a um ground, mas também em relação a um fim interpretativo (Th. 22). Há uma idéia de "progresso" da gênese interpretativa, onde interpretantes dinâmicos são "melhores" que outros, pois se aproximam do interpretante final.

Aqui nos aproximamos da quarta objeção a Peirce: a "parada" da semiose.

Peirce diz: "Eu não nego que um conceito ou signo mental geral possa ser um interpretante lógico; mas ele não pode ser o interpretante lógico último, precisamente porque sendo um signo ele possui um interpretante lógico. Ele possui, de certa forma, o caráter de uma definição verbal, e é muito inferior à definição viva que se abre no hábito. Em conseqüência, a explicação mais perfeita que podemos dar de um conceito vai consistir em uma descrição do hábito produzido por este último" [MS 318]. Peirce chama a atenção para o fato de que toda reação a um signo produz inevitavelmente uma mudança de hábito. Acredita Thibaud, que após ter recebido uma série de signos e de tê-los diferentemente interpretado, nossa forma de ser e de agir no mundo se transforme de forma passageira ou definitiva. Uma conduta nova então aparece e Peirce a chama de "interpretante final". Neste nível, reproduz Thibaud, pode-se dizer que a semiose infinita dos interpretantes "pára".

Thibaud tenta minimizar o caráter bizarro desta afirmação de Peirce, em si contraditória (a semiose infinita dos interpretantes pára), ao comentar que esta parada não é final num sentido cronológico, pois nossa vida é interminavelmente preenchida por mudanças de hábitos, mas pode-se dizer que neste nível se produzam modificações da experiência e que a ligação da semiose com a realidade física aparece sob a forma da ação concreta.

O hábito, em Peirce, é o momento em que a interpretação produz mudança de atitude, ele é produto da reação a um signo, nossa forma de agir no mundo se transforma passageira ou definitivamente. Há uma virada provocada pela ação da interpretação, essa virada estabiliza o conceito, por isso Peirce fala em interpretante final, em parada da semiose. Aí reside, naturalmente, um paradoxo no movimento da interpretação infinita, pois, por mais que se chegue a soluções satisfatórias, qualquer assentamento trará sempre a lembrança da presença e do real, a coisa em si, que Peirce faz questão de refutar em Kant. Pois não há pausas no movimento que se pretende permanente, o rio heraclitiano não suspende periodicamente seu fluxo. Essa dificuldade não é só peirceana mas de todo o pensamento metafísico, o que busca as regularidades e as leis, como se verá mais adiante em Peirce, e é incompatível com a lógica da temporalidade e da mudança. Aceitar que o signo é "coisa viva" suporia em Peirce a exclusão 
de qualquer pretensão ao atingimento de um conceito terminal. A parada da semiose faz entrever um parentesco teórico com o objeto absoluto visto acima.

Mas uma parada não é final "no sentido cronológico", como quer Thibaud. Segundo Petit Robert, o termo arrêt pode ser a ação de deter um movimento, um processo, uma atividade, que pode não se relacionar à temporalidade histórica dos agentes mas vincula-se, no outro caso, como processo, à temporalidade interna do mesmo. Além disso, pode significar também impedir alguém ou algo de agir, capturar como prisioneiro, bloqueio, definições estranhas ao contexto peirceano. Para Thibaud, o outro sentido da parada é o "produção de modificações da experiência" e que a ligação da semiose com a realidade física aparece sob a forma da ação concreta. Mas para produzir modificações não é preciso parar, a própria modificação já é a nova forma alterada, que ocupa o lugar da anterior, nada pára. Tampouco a ação concreta significa que estacionemos em algum lugar no decurso das interpretações infinitas, mas que apliquemos na prática aquilo que provisoriamente nos é dado pelas mesmas interpretações.

Thibaud no diz, em seguida, que no plano cosmológico, a própria natureza possui "hábitos", que seriam as leis ou as regularidades diversas. Seriam os "princípios gerais [que] operam realmente na natureza" [5.101], enquanto que o sentido último ou interpretante final de um signo pode ser concebido como uma lei física testada por uma regra operatória (Th, p. 23). O pragmatismo cai inevitavelmente no positivismo. Peirce opta conscientemente pelo formalismo da ciência voltada ao linear, às regularidades, à mecânica das estruturas, em clara contradição com a lógica dos processos. Se tudo se transforma, se a interpretação é infinita, se o símbolo é coisa viva, então não há lugar para a lei, os "casos idênticos", a busca de categorias, que Nietzsche chamava de "invenção para manter a vontade reativa". Quem aposta nas leis físicas ("os hábitos inveterados tornam-se leis físicas" [6.25; cf.
6.277]) não pode falar no caótico das mudanças permanentes.

E isso é o mesmo que Derrida criticou, páginas atrás, da estrutura, da unidade, da ordem, do sistema, do contexto: o centro, que não é o da estrutura mas está fora dela, orienta a estrutura, equilibra, organiza mas inviabiliza uma estrutura não-organizada.

O sentido de um signo é aquilo que ele diz fazer, ou então, que ele faz. Não é somente dizer, é fazer [5.546]. Mas Peirce vai um pouco além desse pragmatismo elementar: o interpretante final, conhecido como hábito, diz Thibaud, vem ligar entre si os diversos interpretantes (por exemplo, emocionais, energéticos ou lógicos) de um signo a fim de constituir um sistema onde só haja uma simples coleção de fatores. Ele unifica signo, objeto e interpretantes para viabilizar o sentido, que depende da relação triádica mas não se reduz a seus elementos, ele não é empiricamente observável (Th, p. 24). Vê-se aqui traços do idealismo objetivo que Peirce diz seguir: "a única teoria inteligível do universo é a do idealismo objetivo, segundo a qual a matéria é o espírito enfraquecido" [6.25; 6.277].

É uma formulação pessoal desse idealismo objetivo, já que Peirce não o aceita como formulado por Hegel, cuja estrutura "é inabitável", se bem que incorpore algo do sistema hegeliano (a teleologia, a evolução a partir de sucessivas transformações, a idéia de progresso e de melhoria sucessiva).

Para alguns intérpretes, o interpretante final seria um não-signo. Ele é um signo que liga os outros, espécie de Idéia que vai se realizando evolutivamente. Este interpretante, "mesmo que ele possa ser um signo", não é um signo no mesmo sentido que os outros interpretantes (Th., 25). Os demais devem ser interpretados pelo interpretante final para serem unificados; mas, se um interpretante pode ser final é porque ele permite uma ação concreta em relação ao objeto representado, o que não seria possível pela simples gênese de interpretantes normais.

Temos, aqui, então, um interpretante 
que não precisa de outros. Paradoxo curioso num sistema que vive da remissão contínua do interpretante ao signo, num ciclo permanente e sem parada; exceção que Peirce faz para poder isolar aquilo que vai representar a Idéia, que vai promover a realização desse conceito e, assim, hipostasiá-lo do quadro recursivo que o caracterizava. Ele não necessita dos outros mas engendra outros interpretantes, o que o torna um "signo de outro tipo" [5.491].

Diante desta aporia não resta a Peirce outra saída senão elaborar o conceito de idealismo condicional [5.494], segundo qual, a realidade não é um dado mas o resultado percebido através de regras de ação, ações que conduzem a uma seqüência infinita de consensos provisórios sobre os resultados concretos da semiose. Isto supõe não contradizer o interpretante final: se a semiose pára a todo momento, diz Thibaud, por força das ações concretas produzidas enquanto interpretantes finais - ele reinicia logo, como fênix, dando origem a novos processos interpretativos, isto é, a novos sistemas semióticos.

O intérprete francês de Peirce diz aqui que a intuição peirceana parece neste momento se enraizar filosoficamente na recusa clara à coisa em si kantiana. O objeto "absoluto" que Peirce analisa como "limite", aparece como limite entre dois infinitos: o infinito do lado da pesquisa das condições necessárias, isto é, dos fundamentos últimos (recusa de se deter sobre a coisa em si, última, não-conhecível), e do lado da pesquisa das condições de possibilidade: todo sistema semiótico torna possível a emergência de um novo sistema (Th., 25-26).

A base é inegavelmente hegeliana: em Peirce encontra-se, como em Hegel, a filosofia como forma de compreensão, a dualidade entre o que se pensa da coisa e o que ela é verdadeiramente, o conceito não como uma construção intelectual mas como interioridade e vida das coisas (pensar a Idéia é pensar o real). Para Hegel, como para Peirce, o absoluto não é nada reservado, fechado, mas um meio (no mesmo sentido de meio ambiente), sendo que a razão não remete a estruturas inteligíveis bem compreendidas mas a um dinamismo que comanda a evolução dos próprios fenômenos. Espírito e idéia não são idéias platônicas reinando acima dos homens, elas revelamse elas mesmas, progressivamente.

Mas Peirce não incorpora Hegel totalmente. Não se vê traços da identidade dos contrários, do tríplice movimento da Idéia (se bem que se possa ver uma interessante homologia entre o espírito subjetivo - o espírito em si como verdade da natureza - e a afecção do primeirismo; o espírito objetivo - a conciliação entre o universal e o individual - e a relação da sensação com o sujeito no secundismo; o espírito absoluto - o retorno do Espírito - e a significação e o hábito do terceirismo), da presença da história viva em contato com o real, do movimento de alienação. Mas a teleologia e o finalismo estão lá, assim como a concepção implícita de que o real é racional e, por último, mas não menos importante, a concepção de Idéia no sentido mesmo de "corporificação do Verbo", vista, à semelhança do sentido hegeliano de conceito (Deus é $o$ conceito).

Como Rorty, Peirce não acredita na possibilidade do incogniscível. Como os maus leitores do Tractatus, ele acharia que "aquilo que se pode dizer diz-se claramente". Não há limites para a razão, diferente do que pensava Wittgenstein e seu enigma, seu problema da vida e seu místico; ou do que supunha Nietzsche com o inexprimível. "Nós não temos um conceito daquilo que é absolutamente “incogniscível" [5.265]. Já vimos isso na segunda objeção a Peirce.

De qualquer forma, mesmo sob a releitura hegeliana, a noção de absoluto guarda um quê de suspeita. Pois Hegel, rejeitando as idéias platônicas de algo que paira acima dos mortais, mantém-se preso a uma revelação religiosa. Caberia à Igreja cristã realizar, na ordem objetiva da história, o Espírito absoluto que, segundo Hegel, Cristo revela; contudo, o catolicismo, obscurecido de exterioridade, morreu na Idade Média, enquanto que o protestantismo, desvalori- 
zando suas obras, desprezando o mundo, se fechou na interioridade e volatizou a unidade da Igreja. Logo, o Estado deve substituí-la, deve oferecer a identidade do real com o racional, ou seja, conformar a humanidade à lógica absoluta desvelada, o cristianismo. Não se pode esquecer que o Espírito absoluto realiza-se a si mesmo sob a forma de verdade revelada por sentimento (religião) e sob a forma de verdade expressa (conhecimento racional puro).

Peirce faz recurso do absoluto, como vimos acima, onde ele diz que uma seqüência sem fim de representações, cada uma representando aquela que a precede, pode ser concebida como tendo um objeto absoluto como limite. O sentido de uma interpretação não pode ser outra coisa que uma representação... De sorte que existe aí uma regressão infinita. Definitivamente, o interpretante nada mais é do que uma representação que recebe, abrindo caminho, a chama da verdade. [1.339, grifo nosso]. O parentesco com o conceito hegeliano não pode ser ignorado.

Chegamos, por fim, ao falibilismo e ao conceito de verdade. A construção de sistemas semióticos, diz Thibaud, não deve ter um fim: todo o sistema é uma configuração provisoriamente estabilizada num fluxo infinito (Th., 26). O especialista francês diz aqui que Peirce intui, através da noção de interpretante, a diacrônica desestruturação e restruturação de sistemas semióticos. Estamos num campo familiar a Gilles Deleuze e Félix Guattari, tratados no Cap. 3, o das noções de desterritorialização e reterritorialização. Peirce chama a isso de sinequismo finalista: a continuidade como algo de primeira importância para a filosofia, "a coalescência, o devir contínuo, o devir governado por leis... que só são fases de um só e mesmo processo de crescimento da razão" [5.4] e da filosofia peirceana do falibilismo: "a verdade é a concordância de um enunciado abstrato com o limite ideal, em direção ao qual irá tender a pesquisa, que não terá fim no produzir da crença científica, concordância que o enunciado abstrato pode ter em virtude de seu caráter inexato e parcial confesso, e esta confissão é um elemento essencial da verdade" [5.565].

Peirce, inspirado no iluminismo e no positivismo, fala no "crescimento da razão" e define a verdade como aproximação entre um enunciado abstrato (partial, inexato) e "limite ideal" para onde tendem as pesquisas, mas que é inesgotável, não termina. Thibaud adverte que nesta altura Peirce alterou uma afirmação feita em 1873, segundo a qual, ele falava de um último estágio do saber "que nenhuma pesquisa posterior irá questionar" [7.319], e que não deveria ser levado a sério, como o fez Habermas.

Deixando de lado essas excentricidades de Peirce, devemos nos fixar na tentativa de compreensão de seu conceito de verdade. Em primeiro lugar, o uso do termo razão é suspeito, e isso já na sua época, através das denúncias de Nietzsche (entre outros: Sobre a verdade e a mentira, Humano demasiado humano, mas principalmente no Crepúsculo dos ídolos). Suspeito porque, muito além da noção de guia do espírito para investigação refletida e ordenada, da faculdade de formar conceitos e julgamentos, de organizar conhecimento em sistemas, de dar um sentido ao universo e mesmo uma ordem, razão tornou-se sinônimo de dominação. E não apenas no campo da política e da tecnologia, como expõe Habermas em seu "Técnica e ciência como ideologia'", mas também no campo do próprio saber, como épistème.

Já vimos exaustivamente quanto a racionalidade embutida no positivismo lógico deixou à margem todos os conhecimentos "incomodantes", todas as iniciativas irredutíveis à lógica e à experiência. Lyotard fala, nesse sentido, de dois tipos de saber, um positivista, que colabora com o funcionamento de todo o sistema, e um crítico ou reflexivo, que lhe opõe obstáculos éticos. Peirce, pelo que se viu acima, posiciona-se pelo primeiro tipo (veja-se as objeções 2 e 5). Seus argumentos não só consubstanciaram a matemática dos filósofos analíticos de Cambridge mas seguiram na mesma di- 
reção empírica e fenomenológica da ciência "rigorosa", excluindo do campo o não-empírico como fez no passado a Igreja com as heresias.

A razão como princípio, como apontado no volume 1 desta Trilogia, pode tender para um jogo de poder em que não somente o não-linear (o diferente, o estranho, a alteridade) seja excluído, mas igualmente os próprios pesquisadores: é o que se chama a taylorização da pesquisa. Contra ela, uma pitada de suspeita em relação à razão poderia, antes, desenvolver o espírito crítico. É o caso dos "pessimistas" da geração vienense do início do século 20: Musil, Kraus, Hofmannsthal, Loos, Schönberg, Broch, mas também os filósofos Mach e Wittgenstein. A força de Wittgenstein, conforme Lyotard, consistiu em não colocar-se ao lado do positivismo que o Círculo de Viena desenvolvia e de traçar em sua investigação dos jogos de linguagem a perspectiva de um outro tipo de legitimação que não fosse o desempenho. O "sorriso dissimulado da ciência", conclui o filósofo francês, parafraseando Musil, ensinou-lhes a dura sobriedade do realismo.

Mas o termo razão, usado por Peirce, pode ser deixado de lado. A noção de verdade é semelhante à de Umberto Eco e à de Gadamer. Este último, como visto no início do Capítulo, acreditava que o pesquisador pudesse defender-se do arbítrio e de suas limitações, oriundas de hábitos mentais inconscientes, olhando "para as próprias coisas". Com isso, saperar-se-iam as confusões vindas de seu íntimo, podendo-se esboçar preliminarmente um sentido, começando assim a interpretação. O trabalho, continuamente revisto pelos resultados sucessivos, poderia, então, substituir paulatinamente os preconceitos por conceitos mais adequados. É o inexato e o parcial de Peirce.

Tudo isso poderia ser em parte válido (considerando-se evidentemente as críticas feitas ao modelo Gadamer-Eco por Derrida: a existência de um conselho de autorizados que legitima as verdades descobertas aqui e ali; o academicismo da validação científica que Eco apropria de Popper; o atingimento da verdade final no final da cadeia de segredos), já que nem Derrida nem seus seguidores recusam a interpretação, eles só dizem que ela não pode se arvorar a chegar à verdade. Uma coisa é interpretar, outra, bem diferente, é pleitear atingimento de uma verdade ou mesmo de criar uma hierarquia em que algumas interpretações estão a menos passos dela do que outras. É possível fazer-se, por exemplo, $n$ leituras de Nietzsche: em umas denunciar a intenção de domesticá-lo, como fez Heidegger; em outras, a intenção de democratizar seu totalitarismo; em outras, ainda, ver nele o inspirador de uma nova moral. Todas são válidas, ao mesmo tempo em que todas são falsas. Não é isso que interessa. O que de fato importa, de fato, é ler Nietzsche e trazer para os tempos de hoje o que se aplica verdadeiramente à nossa realidade, o que a explica, o que nos ajuda a melhor tratar com ela. As interpretações só podem ser instrumentos de apoio, jamais tábuas da lei.

\section{Detalhamentos}

Peirce e as definições do lítio: "Se você procura num manual de química a definição do lítio, pode ser, dir-se-á, que se trate deste elemento cujo peso atômico é aproximadamente 7. Mas se o autor é dotado de um espírito mais lógico, ele dirá que se você procura, entre os minerais vítreos, translúcidos, cinza ou brancos, muito duros, que se esmigalham e não são solúveis, que comunicam uma cor vermelho vivo à chama incolor, este mineral, estando triturado com o calcário ou pela morte aos ratos... depois fundido, pode ser em parte dissolvido no ácido muriático; e se se faz evaporar esta solução e se extrai o resíduo graças ao ácido sulfúrico, pode-se, após o refinamento, converter pelos processos clássicos em cloreto, o qual, obtido em estado sólido, fundido e eletrolisado... produzirá um glóbulo de um metal argentado róseo flutuando sobre a essência mineral; o material resultante de tudo isso é um espécime de lítio". [2.330] 
"Depth" e "breadth" em Peirce: O "profundo" de um termo significa "todas as características reais... que se pode atribuirlhe" [2.408], isto é, sua "compreensão" [2.407] e o "leve" (breadth: ar, sopro) remete a "todas as coisas reais às quais ele é predicável" [2.407], isto é, sua "extensão".

Peirce fala de seus três interpretantes na sua Carta a Lady Welby (v. Bibliogr).

Habermas critica Peirce no livro Conhecimento e interesse, p. 125 .

\section{Referências}

Peirce, C.S. : Critérios das citações

Quando precedidas de MS e feitas entre colchetes, referem-se aos manuscritos inéditos, conforme a numeração feita por R. S. Robin, Annotated Catalogue of the Papers of Charles S. Peirce, Amherst, 1967; aquelas feitas entre colchetes, sem mais, são do Collected Papers of Charles Sanders Peirce, Vols. 1 a 6, editadas por C. Hartshorne e P. Weiss; volumes 7 e 8, editadas por A.W. Burks, Cambridge, 1931-1958. 0 primeiro algarismo é o número do volume e a numeração subseqüente, a da página. Já aquelas colocadas entre parêntesis são da edição brasileira desta mesma última obra, publicada pela Abril Cultural: Peirce e Frege, Os Pensadores, São Paulo, Abril, 1980.

Peirce, C.S. "Carta a Lady Welby", cf. Hardwick, C., org., Semiotics ans Significs: The Correspondance between C. S. Peirce and Victoria Lady Welby. Bloomington, 1977, p. 111

Deledalle, Gérard, "Peirce", in Dictionnaire. des Philosophes., Paris, Albin-Michel, 1998,p. 1180-1181.

Derrida, Jacques. De la Grammatologie. Ed. de Minuit, 1967, Paris, p. 72.

Gandillac, Maurice de, "Duns Scot", in: Dictionnaire des Philosophes, op. cit., p. 486-495.

Habermas, J. Conhecimento e interesse. Rio de Janeiro, Zahar, 1982, P. 125.

Lyotard, J.F. O pós-moderno. Rio de Janeiro, José Olympio, 1979.

Marcondes Filho, Ciro. A produção social da loucura. São Paulo, Paulus, 2003.
Idem. A Sociedade Frankenstein. Ed,. do Autor, 1991. Ver: www. eca.usp.br/nucleos/filocom

Idem. Da arte de envenenar dinossauros e outros textos mediáticos. São Paulo, Com-Arte, 2003.

Short, T.L. "Semiosis and Intentionality", Transactions of the C. C. Peirce Society, 1981, vol. 17, no. 3, p. 216.

Thibaud, P. "La notion peircéenne d'interprétant", Dialectica, Vol. 37, Fasc. 1, 1983, pp. 4-35 